\title{
Combined Impacts of Two Type's Cold Storage and Microwave Radiation on Stored Products Insects and Wheat Seed Viability
}

\author{
Nasim Bayramzadeh $^{* 1}$ and Ali Asghar Pourmirza ${ }^{2}$ \\ 1,2 Department of Plant Protection, Agricultural Faculty, Urmia University, Urmia, IRAN. \\ E-mail: apourmirza1@yahoo.com.
}

\section{ABSTRACT}

Microwave radiation in conjecture with two types of cold storage were used to control adults of red flour beetle, Tribolium castaneum (Herbst) (Coleoptera: Tenebrionidae) and lesser grain borer, Rhyzopertha dominica (F.) (Coleoptera: Bostrichidae). The mortality rate of the insects at $200 \mathrm{~W}$ microwave power level, different exposure times $(0,2,4,6$ and $8 \mathrm{~min})$, for $48 \mathrm{~h}$ pre and post cold storage period was determined. A direct relationship between mortality rates and exposure times was detected. Susceptibility of the insects in implementation radiation priori or post cold storage execution was significantly different. Apparently, when the insects were exposed to microwave radiation prior to cold storage, the mortality rates were increased. In comparison, the adults of wheat flour beetle were more tolerant than the corresponding adults of the lesser grain borer. Wheat germination rate was diminished by post cold storage microwave radiation procedure. The plumule length did not reduce after exposure to microwave energy and cold storage. Together, data suggest concurrent application of microwave radiation followed by cold storage could be a potential measure for control wheat stored-product beetles.

Keywords: Heat manipulation, toxicity, stored-product, insects, wheat seed.

\section{INTRODUCTION}

Cereal grains including wheat are the major source of food for human beings and include rich vitamins, minerals, carbohydrates, fats, oils, and proteins. It is essential that the availability of cereal grains is consolidated by the development of effective storage practices to minimize losses in stores (Schöller et al., 1997). The widespread and intensive use of synthetic insecticides for the control of stored-grain insects has led to serious problems including insecticide resistance of pest insects, health issues, and lethal effects on non-target organisms (Jovanovic et al., 2007; Lu $\& \mathrm{Wu}, 2010)$. Thus, there is an urgent need to develop safe alternative options for stored products pest management system. Temperature is one of the principal factors delimitating survival and reproduction ability of insects. Lethal temperatures are those above or below the suboptimum which will eventually kill the organism. Pest management through temperature manipulation is receiving renewed interest as a nonchemical method with lack of residual problems (Hallman \& Denlinger, 1999). Insects in stored wheat can be controlled by manipulating the physical environment or by applying physical treatments to the wheat mass and associated insect species. Mullin (1995) stated that microwave heating is based on the transformation of alternating electromagnetic field energy into thermal energy by affecting polar molecules of a material. The advantages of microwave energy as a pest control measure include the absence of undesirable residues in the foods stuff, avoiding undue resistance of pest insects and little alteration either in the physicochemical properties 
or the nutritive value of the treated food stuffs (Vadivambal et al., 2007; Zhao et al., 2007).

Taking this point of view, Warchalewski et al.(2000) and Vadivambal et al. (2007) stated that microwave energy is not persistent in the environment and does not poses hazardous impacts to foodstuffs and consequently the undue hazardous impacts on health issue could be avoided. Exposure to microwave energy could cause physical injuries and reduce reproduction rates in surviving insects. Wang and Tang (2001) stated that insects under microwaves radiation are prone to some types of stress such as controlled atmosphere and cold ambient conditions. Gasemzadeh et al. (2010) using two stored-products insects identified synergistic impact between continuous and intermittently microwave radiation and cold storage. In this line Gould (1994) reported that cold storage treatments have been developed for quarantine purposes and for use against exotic pest insects such as fruit flies.

There is widely held that germination rate provides the maximum germination potential of a seed lot and this can be used to compare the quality of different seed lots and also estimate the field planting value. For preservation of seeds quality is essential that the seed is tolerant to the microwave radiation and cold storage treatment. Seed viability could be a good indicator of wheat seed quality after exposure to the treatments in question. Based on ISTA (1976) principals, hence, in this study two measurements related to wheat seed quality were investigated.

A review of the literature revealed the paucity of information upon combined effects of microwave radiation with different types of cold storage execution method on stored-products insects and wheat seed viability. With retrospect, to fill such a void the current study was undertaken. The objectives of this research were as follows:

- To determine a combined effects of microwave radiation and two types cold storage execution methods on $T$. castaneum and $R$. dominica adults, and

- to evaluate the combined impacts of microwave radiation and different cold storage execution methods on wheat seed viability.

\section{MATERIALIS AND METHODS}

\section{Test insects}

Stock cultures of, Tribolium castaneum (Herbst) (Coleoptera: Tenebrionidae) and Rhyzopertha dominica (F.) (Coleoptera: Bostrichidae) were collected from local mills, stores, and shops in Urmia $\left(37.39^{\circ} \mathrm{N} 45.4^{\circ} \mathrm{E}\right)$, a town in Iran in 2009. These insects were chosen due to their economic importance throughout the world including Iran. Cultures were established and maintained on heat-sterilized food at $27 \pm 2{ }^{\circ} \mathrm{C}$ and $60 \pm 5 \% \mathrm{RH}$ inside 1000-ml glass jars covered with pieces of muslin cloth fixed with rubber bands. All insects were cultured under low-density conditions to ensure proper development and equal size resultant adults. Insects were reared for two generations before initiation of the experiments. T. castaneum was reared on a 50:50 mixture of wheat flour and cornmeal. This mixture contained $5 \%$ brewer's yeast. $R$. dominica was reared on soft red winter wheat.

\section{Bioassays}

This study was carried out at Urmia University in 2009. All experiments were conducted using a kitchen type, $2450 \mathrm{MH}_{\mathrm{z}}$ microwaves oven (Butane, BC $320 \mathrm{~W}$ ) with capability of producing 100 through $1000 \mathrm{~W}$ microwave power. Prior to each experiment for a given time preliminary power level settle test was carried out to 
determine a range of power level that would produce $\approx 25-75 \%$ mortality at the lowest and the highest levels, respectively (Robertson et al., 2007).

The experiments were carried out according the following two fashions, 1: the insects exposed to radiation and then after kept at cold storage, 2: the test procedure was vice versa of the previous method.

For each experimental unit, using a fine sable brush mixed sex of 1-7 days old adult insects were counted out in batches of 15 on to Petri dishes containing $2 \mathrm{~g}$ of rearing medium; then after, each Petri dish was placed in the microwaves generator oven. Based on preliminary experiment's results and functionality considerations 200 $\mathrm{W}$ power level was chosen for further trials. The insects were exposed to $200 \mathrm{~W}$ power level for $0,2,4,6$ and 8 min either prior or post treatment with cold storage (3 $\pm 1^{\circ} \mathrm{C}$ ) for $48 \mathrm{~h}$. At the end of each experiment insects were maintained on their food under rearing conditions for $24 \mathrm{~h}$ to recover. In each bioassay, mortality was recorded after recovery period. Those insects that did not move when lightly probed or shaken in the light and mild heat were considered dead. After $24 \mathrm{~h}$ of incubation, the mortality data were recorded.

The experimental units and bioassay procedures were identical in all trials. In each trial, the untreated control group was treated identically except that no microwaves radiation and cold storage treatment was employed. The treatments were replicated four times on four different days. In each bioassay, results of all replicates were pooled.

\section{Seed viability tests}

Germination tests as seed viability criterion were conducted according to the principles stated in International Seed Testing Association (ISTA, 1976) methods. Seeds of soft red winter wheat were exposed to microwave radiation at a fixed power level of $200 \mathrm{~W}$ for $8 \mathrm{~min}$. For each treatment fifty treated seeds were saturated with 50 $\mathrm{ml}$ of distilled water and wrapped in two rolled crepe filter papers (500 by $330 \mathrm{~mm}$ each). The seeds were arranged $3 \mathrm{~cm}$ apart on the top of the sheet, and the lot was covered by folding the lower half over them. Each doubled sheet was saturated with water and loosely rolled from one side to the other, perpendicular to the base. It was then held together with a rubber band and put in an upright position in the germinator cabinet at $20^{\circ} \mathrm{C}$. Untreated seeds served as control standards for comparison. Each experiment was replicated four times on $4 \mathrm{~d}$. The number of germinated seeds was counted after 4 and $8 \mathrm{~d}$, and the mean plumule length of 50 seedlings was determined at $8 \mathrm{~d}$.

\section{Data analysis}

Mortality data were subjected to appropriate transformation prior analysis. $\mathrm{LT}_{50}$ values and associated statistics were estimated by subjecting mortality data to the maximum likelihood program of probit analysis Robertson et al. (2007) using SPSS (1999) software. The values and significance of $\chi^{2}$ and the $95 \%$ CI for potency ratios were determined (Norúsis, 2008). Parallel regression lines were also compared using overlapping confidence limits $(P \leq 0.05)$ of relative potencies as the criterion to detect significant differences in mortality. Analysis of variance was used to check the significance of differences between mortality of insects at different cold storage and radiation exposure time, and also differences in the mortality of different insect species. In seed viability tests, the data were normalized by using arcsine-square-root transformation; the data then were analyzed using one-way analysis of variance (ANOVA) followed by Tukey's honestly significant difference test to determine statistical differences between means at $P \leq 0.05$. Student's t-test was used for comparing the means of two independent groups. 


\section{RESULTS}

In terms of the insect mortality rates, based on collected data, a direct positive relationship trend between mortality rates and microwave exposure times was observed in either test insects. In this line, mortalities of $T$. castaneum adults at 2, 4, 6 and $8 \mathrm{~min}$ exposure times with $48 \mathrm{~h}$ cold storage post radiation state were $28.33,55$, 83.33 and $98.33 \%$, respectively. However, when cold storage period was $48 \mathrm{~h}$ prior to microwave radiation, the corresponding mortalities were decreased to some extent and secured 18.33, 41.66, 78.33 and 86.66\%, respectively (Fig. 1). In the case of $R$. dominica, at the first scenario mortalities obtained 30, 63.33, 91.66 and 100\%, respectively but in the second scenario mortalities rates were 18.33, 45, 73.33 and $88.33 \%$, respectively (Fig. 2).

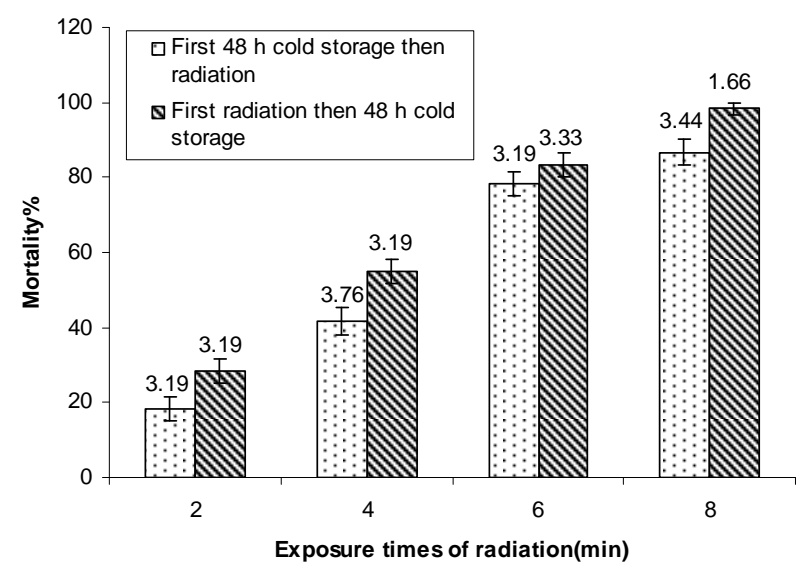

Fig. 1: Mortality percentage of T. castaneum at $200 \mathrm{~W}$ power level and different exposure times.

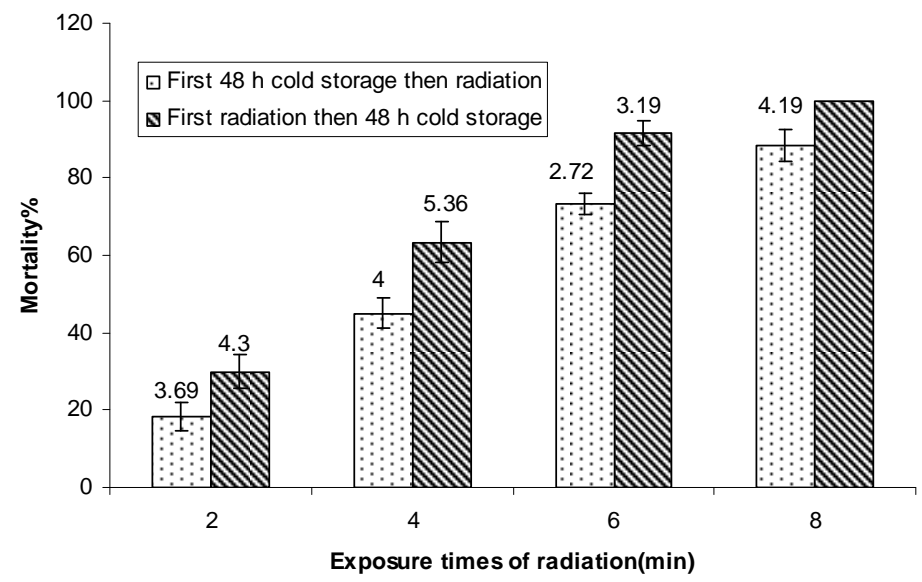

Fig. 2: Mortality percentage of $R$. dominica at $200 \mathrm{~W}$ power level and different exposure times.

Tables 1 and 2 depicted the results which imply that there was a non significant difference in the susceptibility of the insects in using radiation prior or post cold storage execution. However, both insect species were more susceptible to microwave radiation when stationed at cold storage post microwave radiation. The slopes of the dose-response are relatively steep and mortality rates between the highest and lowest were low (Tables $1 \& 2$ ). This is an indication of homogeneity of the population in sample site. 
Table1: Susceptibility of T. castaneum either in pre or post cold storage states to microwave radiation.

\begin{tabular}{|c|c|c|c|c|c|c|}
\hline $\begin{array}{l}\text { Radiation } \\
\text { execution }\end{array}$ & $\begin{array}{c}\mathrm{LT}_{50} \\
\text { (min/insect) }\end{array}$ & $\begin{array}{l}\text { Confidence } \\
\text { limits }\end{array}$ & Intercept & Slope & $\begin{array}{c}\chi^{2 \mathrm{a}} \\
(\mathrm{df}=2)\end{array}$ & $P$ \\
\hline Prior to cold storage & 3.26 & $0.29-5.37$ & 3.03 & 3.84 & 5.71 & $0.06^{\mathrm{ns}}$ \\
\hline Post to cold storage & 3.99 & $3.49-4.48$ & 2.86 & 3.56 & 3.05 & $0.21^{\mathrm{ns}}$ \\
\hline $\mathrm{RMP}_{50}(95 \% \mathrm{CL})$ & 0.79 & $0.55-1.05$ & & & & \\
\hline Parallelism test & & & & & 0.08 & $0.86^{\mathrm{ns}}$ \\
\hline
\end{tabular}

Table 2: Susceptibility of $R$. dominica either in pre and post cold storage states to microwave radiation.

\begin{tabular}{|c|c|c|c|c|c|c|}
\hline $\begin{array}{l}\text { Radiation } \\
\text { execution }\end{array}$ & $\begin{array}{c}\mathrm{LT}_{50} \\
\text { (min/insect) }\end{array}$ & $\begin{array}{c}\text { Confidence } \\
\text { limits }\end{array}$ & Intercept & Slope & $\begin{array}{c}\chi^{2 \mathrm{a}} \\
(\mathrm{df}=2)\end{array}$ & $P$ \\
\hline Prior to cold storage & 2.87 & $0.76-4.37$ & 3.08 & 4.21 & 5.28 & $0.07^{\mathrm{ns}}$ \\
\hline Post to cold storage & 3.93 & $3.44-4.42$ & 2.96 & 3.43 & 1.57 & $0.45^{\mathrm{ns}}$ \\
\hline $\mathrm{RMP}_{50}(95 \% \mathrm{CL})$ & 0.70 & $0.57-0.83$ & & & & \\
\hline Parallelism test & & & & & 0.83 & $0.36^{\mathrm{ns}}$ \\
\hline
\end{tabular}

T-statistics revealed that, the susceptibility of the insects at 6 and $8 \mathrm{~min}$ microwaves radiation were highly significant (Tables $3 \& 4$ ). As a whole, in post radiation cold storage state more mortality rate was detected. Therefore, steps should be taken to promote population stability through integration of all IPM program tools such as judiciously implementation of control agents such as feasible non-chemical control options.

Table 3: Mortality (mean \pm standard error) and $\mathrm{T}$ value of $T$. castaneum exposed to microwave radiation and cold storage at $200 \mathrm{~W}$ power levels.

\begin{tabular}{cccc}
\hline $\begin{array}{c}\text { Exposure times of } \\
\text { radiation (min) }\end{array}$ & Radiation execution & Mean \pm SEM & T value (df=6) \\
\hline \multirow{2}{*}{2} & Prior to cold storage & $4.25 \pm 0.629$ & $1.686^{\mathrm{ns}}$ \\
& Post to cold storage & $2.75 \pm 0.629$ & \multirow{2}{*}{$1.429^{\mathrm{ns}}$} \\
4 & Prior to cold storage & $8.25 \pm 0.479$ & \multirow{2}{*}{$1.083^{\mathrm{ns}}$} \\
& Post to cold storage & $6.25 \pm 1.315$ & \\
6 & Prior to cold storage & $12.50 \pm 0.500$ & $2.049^{*}$ \\
\hline
\end{tabular}

* Statistical significance exists between mean mortality rates at 0.05 levels.

Table 4: Mortality (mean \pm standard error) and $T$ value of $R$. dominica exposed to microwave radiation and cold storage at $200 \mathrm{~W}$ power levels.

\begin{tabular}{cccc}
\hline $\begin{array}{c}\text { Exposure times of } \\
\text { radiation (min) }\end{array}$ & Radiation execution & Mean \pm SEM & $\begin{array}{c}\text { T value } \\
(\mathbf{d f}=\mathbf{6})\end{array}$ \\
\hline \multirow{2}{*}{2} & Prior to cold storage & $4.50 \pm 0.645$ & $1.635^{\mathrm{ns}}$ \\
& Post to cold storage & $2.75 \pm 0.854$ & $1.593^{\mathrm{ns}}$ \\
4 & Prior to cold storage & $9.50 \pm 1.555$ & $4^{* 3.371^{* *}}$ \\
& Post to cold storage & $6.75 \pm 0.750$ & $2^{*}$ \\
6 & Prior to cold storage & $13.75 \pm 0.479$ & $11.00 \pm 0.408$ \\
\end{tabular}

$\bullet \mathrm{ns},{ }^{*}$, and ${ }^{* *}$ denoted to non significant, significant at 0.05 and 0.01 levels, respectively. 
Parallelism test for $T$. castaneum and $R$. dominica revealed a non significant difference between exposure duration-response lines $\left(\chi^{2}=0.08 ; P=0.86\right)$ (Table 1). A similar trend with $\chi^{2}=0.83 ; P=0.86$ was detected for $R$. dominica (Table 2 ). This could be an indication of target site(s) similarity for two different cold storage methods.

In the case of $T$. castaneum, prediction of relative median potency yielded 0.79 , 0.55 , and 1.05 values for estimate, lower and upper confidence intervals, respectively. Combined effects of microwave radiation and cold storage, therefore, exerted similar level of mortality to the insect in different cold storage state. For $R$. dominica the corresponding values were $0.7,0.57$, and 0.83 in the same order. Therefore, cold storage exerted different levels of mortality to the $R$. dominica in different cold storage state. Together, resultant mortality rate in cold storage after microwave radiation was more pronounced.

The germination rate of wheat after exposure to microwave radiation and plumule length are shown in table 5. The standard error from four replicates of 50 seeds each was less than $3 \%$ of the mean value in all cases. Microwave radiation prior to cold storage significantly decreased the germination potential in comparison with post cold storage microwave radiation. Results from vigor test at 4-d count were unchanged at 8-d count (total germination test). In all cases, the standard error in plumule length was $<0.60$ of the mean value which is an indication of uniformity seed's vigor; and a non-significant difference among the plumule length of treated seeds in comparison with untreated seeds was observed (Table 5).

Table 5: Percentage germinability and plumule length of wheat exposed to microwave radiation and two types cold storage.

\begin{tabular}{ccc}
\hline \multirow{2}{*}{ Treatment } & \multicolumn{2}{c}{ Viability } \\
\cline { 2 - 3 } & $\begin{array}{c}\text { Germination rate }(\%)^{\bullet} \\
\text { Mean } \pm \text { SEM }\end{array}$ & $\begin{array}{c}\text { Plumule length }(\mathrm{mm}) \\
\text { Mean } \pm \text { SEM }\end{array}$ \\
\hline Check & $75.60 \pm 0.47^{\mathrm{a}}$ & $9.90 \pm 0.38^{\mathrm{a}}$ \\
& $71.90 \pm 0.60^{\mathrm{b}}$ & $9.30 \pm 0.44^{\mathrm{a}}$ \\
Pre-radiation cold storage & $75.10 \pm 0.52^{\mathrm{a}}$ & $9.20 \pm 0.52^{\mathrm{a}}$ \\
\hline Post-radiation cold storage &
\end{tabular}

Means within columns with similar letters are not significantly different $(\mathrm{P} \geq 0.05)$ according to

Turkey's test.

•Data were transformed using arcsine square root prior to analysis.

\section{DISCUSSION}

Stored-product insects are serious pests of dried, stored, durable agricultural commodities and of many food stuffs worldwide. It is widely held that control of storedproducts pest insects is essential wherever grain quality is to be maintained. For the control of these pests, particularly in grain, some farmers rely mostly on the treatment of contact insecticide and fumigants to raw cereals. Because such treatments may result in the presence of residues in those products prepared from treated grain, there are restrictions in the level of insecticide residues allowed in such products (Bond, 1984; Brewer et al., 1994). Therefore, the numbers of suitable chemical insecticides that can be used in the control of stored-products insects are limited.

A new approach in stored-products control research could be the use of effective substances or measures that are more compatible with environment. The application of low power level of microwave energy in conjecture with after radiation cold 
storage for $48 \mathrm{~h}$ as an insect control measure may be an appropriate approach to meet this objective.

In current study, microwaves radiation was lethal to test insects. The mechanisms involved in the lethal action of microwaves radiation are previously understood. Taking this point of view Zhao et al. (2007) stated that, exposure to temperature above $55^{\circ} \mathrm{C}$ for short periods of time caused 100 per cent mortality. The hazardous impacts could be due to the high frequency oscillation of the water molecules in the body of the insects. Microwave radiation has deleterious effects on insects such as reduction of reproductive rate, losing body weight and malformation as well (Nelson, 1996). In all treatments, a direct positive relationship between microwave exposure time and cold storage with mortality rate was detected. Between two types of radiation adult insects were susceptible to using microwave radiation before the $48 \mathrm{~h}$ cold storage.

Low temperatures have been used widely to manage pest population in bulk stored grain. Typically, development of stored product insects slows or stops when the temperature drops below $14^{\circ} \mathrm{C}$ Banks and Fields (1995). Therefore, thermal treatments using temperatures higher and lower than the range have been exploited for pest control.

Disinfestations of stored-products with physical control methods such as using microwaves energy coupled with cold storage treatment can be an alternative measure to pesticides in killing insects. Combined application of microwaves power with cold storage treatment could be considered as a potential measure, which helps to reduce stored-products insects' populations in IPM programs. Using microwave radiation and cold storage in these trials significantly affect survival of $T$. castaneum and $R$. dominica.

There is widely held that, physical insects control measures such as heat manipulation are environment friendly and beneficial techniques in any storedproducts insects control system.

Microwave energy is not persistent in the environment and does not hazardous impacts or damage to foodstuff and hence there are no adverse effects on human beings (Warchalewski et al. 2000; Vadivambal et al. 2007). This notion is widely seconded in the literature and in this line, several researches more often have been conducted in the use of microwave radiation alone to control stored-product pests (e.g., Warchalewski et al., 2000; Çetinkaya et al., 2006; Vadivambal et al., 2008; Valizadegan et al., 2009; Lu et al., 2010). In this study the microwave radiation used in conjecture with cold storage the results showed that in all experiments microwaves energy inflected lethal effects to the tested insects. This view is seconded by Valizadegan et al. (2009) who identified a direct relationship between microwave power level or exposure periods and stored-product mortality.

The distinction between live seeds and germinated seeds is important, because microwave radiation along with cold storage may cause injury by retarding germination as well as destruction of germinative capacity. Therefore, decrease in germination rate or plumule length after radiation and cold storage was adequate to prove a deleterious effect of this measure on wheat seed viability.

There looks to be a feeling by experts that an ideal control agent is one that is fast acting, cost and labor-efficient, with acceptable control level of the pest. According to these criteria and collected data, using microwave radiation coupled with post exposure cold storage is merit to be considered as a useful measure in wheat stored-products insects control systems. By speculation such out come also may occur among other similar grains pest species. 


\section{ACKNOWLEDGMENTS}

We would like to gratefully acknowledge the financial support provided to this research by the University of Urmia in Iran.

\section{REFERENCES}

Banks, J. and Fields, P. (1995). Physical method for insect control in stored-grain ecosystems, pp.353-410. In: Stored-Grain Ecosystem (Jayas, D. S., White, N. D. G., Muir, W. E., eds.), NY: Marcel Dekker, Inc. New York.

Bond, E. J. (1984). Manual of fumigation for insect control. Food and Agriculture Organization Plant Production and Protection Paper 54. Food and Agriculture Organization, Rome, Italy.

Brewer, M. S., G. K. Sprouls, and C. Russon. (1994). Consumer attitudes toward food safety issues. Journal of Food Safety 14: 63 -76.

Çetinkaya, N., Ozyardimci, B. and Denli, E., Ic, E. (2006). Radiation processing as a post-harvest quarantine control for raisins, dried figs and dried apricots. Radiation Physics and Chemistry 75: 424-431.

Gasemzadeh, S., Pourmirza, A.A., Safaralizadeh, M.H. and Maroufpoor, M. (2010). Effect of microwave radiation and cold storage on Tribolium castaneum Herbst (Coleoptera: Tenebrionidae) and Sitophilus oryzae L. (Coleoptera: Curculionidae). J. Plant Protection Research 50: 140-145.

Gould, W. P. (1994). Cold storage, pp.119-132. In: Quarantine Treatments for Pests of Food Plants Sharp, (Hallman, G. J. ed.), Westview Press, San Francisco.

Hallman, G. J. and Denlinger, D. L. (1999). Temperature sensitivity and integrated pest management, pp.1-5. In: Temperature Sensitivity in Insects and Application in Integrated Pest Management (Hallman, G. J., Denlinger, D. L. eds.), Westview Press, Boulder, Colorado.

ISTA, International Seed Testing Association. (1974). International rules for seed testing. Seed Science Technology 4: 3-177.

Jovanovic, Z., Kostic, M. and Popovic, Z. (2007). Grain-protective properties of herbal extracts against the bean weevil Acanthoscelides obtectus Say. Industrial Crop and Products 26:100-104.

Lu, H., Zhou, J., Xiong, S. and Zhao, S. (2010). Effects of low-intensity microwave radiation on Tribolium castaneum physiological and biochemical characteristics and survival. Journal of Insect Physiology 56: 1356-1361.

Lu, J. and Wu, Sh. (2010). Bioactivity of essential oil from Ailanthus altissima bark against 4 major stored-grain insects. African Journal of Microbiology Research 4:154-157.

Mullin, J. (1995). Microwave processing, pp. 112-134. In: New Methods of Food Preservation. (Gould, G. W. ed.), Bishopbriggs, Glasgow: Blackie Academic and Professional.

Nelson, S. O. (1996). Review and assessment of radio-frequency and microwaves energy for stored-grain insect control. Transactions of the American Society of Agricultural Engineers 39:1475-1484.

Norusis, M.J. (2008). SPSS 16.0 Guide to Data Analysis. Upper Saddle River, N.J.: Prentice Hall, New York.

Robertson, J. L., Russell, R. M., Preisler, H. K. and Savin, E. (2007). Bioassays with Arthropods. CRC Press, Boca Ratone, FL. 
Schöller, M., Prozell, S., Al-Kirshi, A. G. and Reichmuth, C. (1997). Towards biological control as a major component of integrated pest management in stored product protection. Journal of Stored Products Research 33: 81-97.

SPSS, (1999). SPSS User's Manual. Release 10.0 SPSS, Chicago, IL.

Vadivambal, R., Jayas, D. S. and White, N. D. G. (2007). Wheat disinfestations using microwave energy. Journal of Stored Products Research 43: 508-514.

Vadivambal, R., Jayas, D. S. and White, N. D. G. (2008). Determination of mortality of different life stages of Tribolium castaneum (Coleoptera: Tenebrionidae) in stored barley using microwaves. J. Economic Entomology 101: 1011-1021.

Valizadegan, O., Pourmirza, A. A. and Safaralizadeh, M. H. (2009). Combination of microwave radiation and cold storage for control of Oryzalephilus surinamensis (L.) (Coleoptera: Silvanidae). J. Biological Sciences 9: 231-236.

Wang, S. and Tang, J. (2001). Radio frequency and microwaves alternative treatments for insect control in nuts. Journal of Agricultural Engineering 10:105-120.

Warchalewski, J. R., Pradzynska, A., Gralik, J. and Nawrot, J. (2000). The effect of gamma and microwave irradiation of wheat grain on development parameters of some stored grain pests. Nahrung 44: 411-414.

Zhao, S., Qiu, C., Xiong S. and Cheng, X. (2007). A thermal lethal model of rice weevils subjected to microwave irradiation. J. Stored Prod. Res., 43: 430-434. 